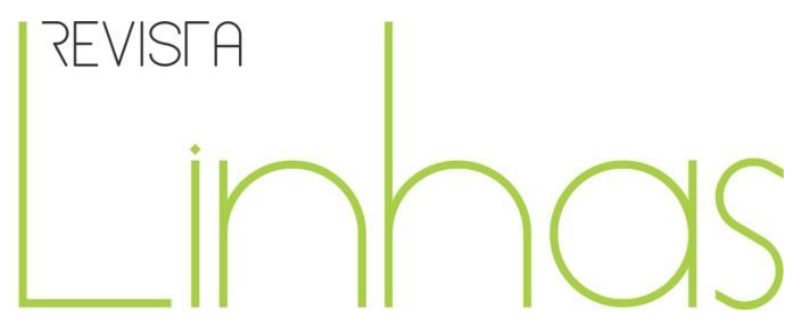

\title{
Prêmios para escolas e professores com base no desempenho acadêmico discente: a experiência do estado do Ceará (Brasil)
}

\begin{abstract}
Resumo
O sistema educacional brasileiro, a fim de atestar a eficácia ou o fracasso das ações escolares, bem como priorizar e redirecionar investimentos públicos, vem implementando políticas de prestação de contas, em que os atores educacionais são corresponsabilizados pelos resultados de desempenho alcançados pela instituição de ensino. Um dos estados precursores foi o Ceará, que há mais de uma década vem fazendo uso da avaliação externa para emitir rankings, classificações e prêmios. Diante dessa experiência histórica, o presente escrito tem como escopo principal discutir sobre a política de responsabilização escolar, reconhecendo e distinguindo seus efeitos (low-stakes e highstakes) no âmbito da administração pública da educação cearense. A metodologia utilizada foi o estudo descritivo-analítico e apoia-se nas concepções de pesquisadores renomados acerca da política de responsabilização - Afonso (2009a, 2009b, 2010); Brooke (2006); Castro (2009). A conclusão a que se chega é a de que o estado do Ceará legitima a política de prestação de contas com consequências low-stakes e high-stakes, pois faz uso dos resultados do Sistema Permanente de Avaliação da Educação Básica do Ceará para publicização dos rankings escolares, atribuição de mérito e demérito das escolas, premiação institucional, bonificação docente e também como medidas administrativas para ajudar e/ou fechar escolas com níveis de desempenho considerados insuficientes. Com efeito, a política de responsabilização tem colaborado para o aumento do percentual de crianças no nível de proficiência desejável de alfabetização. Em contrapartida, tende a reorientar o trabalho escolar, determinando o quê, como e para quê ensinar à revelia da autonomia e pluralidade das ações docentes.
\end{abstract}

Palavras-chave: Avaliação Educacional. Política de Responsabilização. Premiação Escolar.

\author{
Karlane Holanda Araújo \\ Universidade Federal do Ceará - \\ UFCE - Fortaleza/CE - Brasil \\ Karlane.araujo@ifce.edu.br \\ Raimundo Hélio Leite \\ Universidade Federal do Ceará - \\ UFCE - Fortaleza/CE - Brasil \\ rhleite@terra.com.br
}

Wagner Bandeira Andriola

Universidade Federal do Ceará UFCE - Fortaleza/CE - Brasil w_andriola@yahoo.com

\section{Para citar este artigo:}

ARAÚJO, Karlane Holanda; LEITE, Raimundo Hélio; ANDRIOLA, Wagner Bandeira. Prêmios para escolas e professores com base no desempenho acadêmico discente: a experiência do estado do Ceará (Brasil). Revista Linhas. Florianópolis, v. 20, n. 42, p. 303-325, jan./abr. 2019. 


\section{Awards for schools and teachers based on academic performance: the experience of the state of Ceará (Brazil)}

The Brazilian educational system, in order to attest to the effectiveness or failure of school actions, as well as to prioritize and redirect public investments, has been implementing accountability policies, in which the educational actors are jointly responsible for the performance results achieved by the educational institution. One of the precursor states was Ceará, which has been using external evaluation for more than a decade to issue rankings, rankings and awards. In view of this historical experience, the main purpose of this paper is to discuss the policy of school accountability, recognizing and distinguishing its effects (low-stakes and high-stakes) within the public administration of education in Ceará. The methodology used was the descriptive-analytical study and is based on the conceptions of renowned researchers about the policy of accountability - Afonso (2009a, 2009b, 2010); Brooke (2006); Castro (2009). The conclusion reached is that the state of Ceará legitimizes the policy of accountability with low-stakes and high-stakes consequences, as it makes use of the results of the Permanent System of Evaluation of Basic Education of Ceará to publicize the rankings School awards, school merit and demerits, institutional awards, teacher bonus and administrative measures to help and / or close schools with insufficient levels of performance. Indeed, accountability policy has been instrumental in increasing the percentage of children at the level of desirable literacy proficiency. On the other hand, it tends to reorient school work, determining what, how and for what to teach in the absence of autonomy and plurality of teaching actions.

Keywords: Educational Assessment. Accountability Policy. School Awards. 


\section{Introdução}

A partir do fenômeno da globalização ${ }^{1}$, na década de 1990, imprimiu-se uma reforma na regulamentação das políticas educativas, em que o ideário de educação para todos norteia-se nos parâmetros de produtividade, eficácia e qualidade, em busca de atender às demandas do capital (ANDRIOLA, 1998). Mecanismos de gestão e avaliação dos resultados escolares estão sendo desenvolvidos a fim de mensurar o progresso relativo e absoluto do sistema educacional, atestar a eficácia ou o fracasso das ações escolares, bem como priorizar e redirecionar investimentos públicos (ANDRIOLA, 1999).

A necessidade por maiores informações sobre os resultados dos sistemas escolares tem sido respondida pela implementação de políticas de responsabilização, em que alunos, professores, gestores e outros membros da equipe escolar são corresponsabilizados pelos resultados de desempenho alcançados pela instituição de ensino (BROOKE, 2006).

A política de responsabilização, no contexto educacional, significa, acima de tudo, a associação entre resultados de aprendizagem e consequências para o distrito educacional, a escola, os professores ou os alunos. Tal medida pode ser aplicada com nível de pressão/consequência mais altos, high-stakes, e mais baixos, low-stakes².

Nos Estados Unidos, as políticas de responsabilização ou de prestação de contas foram introduzidas nos anos de 1980. Brooke (2006) evidencia que o estímulo inicial foi a publicação, em 1983, do relatório Uma nação em risco (GARDNER et al., 1983), que desenhou um quadro alarmante de perda de competitividade provocada por um declínio nos padrões educacionais. Ao longo das últimas décadas, o entusiasmo pelas medidas de responsabilização nos Estados Unidos só tem aumentado. Testes em larga escala, publicização dos resultados educacionais, comparação dos índices escolares e medidas de incentivo e sanções compensatórias mediante o alcance das metas delineadas fazem parte da política educacional adotada nos estados norte-americanos.

\footnotetext{
${ }^{1}$ Globalização é um conceito contestado, dada a polissemia que evoca. Aqui se usa o termo no sentido do fenômeno da mundialização da economia, resultado da terceira revolução tecnológica, da formação do livre comércio e blocos econômicos interligados e da crescente interligação e interdependências dos mundos físicos e financeiros, em escala planetária (GIANNETTI, 1997). No bojo dessas mutações, instaurouse uma nova ordem ideológica que impacta na homogeneização da cultura.

${ }^{2}$ Nessas expressões, o substantivo da língua inglesa stake significa "[...] o valor colocado em jogo pelo apostador”, já os adjetivos “high" e "low” significam alto e baixo, respectivamente (ARAÚJO, 2016, p. 57).
} 
Não obstante a esses ensaios pioneiros nos Estados Unidos, há que se destacar, conforme Trevisan e Bellen (2008) que, inicialmente, a avaliação educacional dava ênfase ao fornecimento de informação útil para gestores, garantindo o feedback acerca do objeto ou entidade avaliada. Posteriormente, na década de 1980, quando se buscava mais eficiência na alocação de recursos, o foco foi direcionado para a (re)alocação fundamentada em critérios orçamentários. Já na década de 1990, última constatada na literatura, sua função passou a ser de legitimação por meio do questionamento do papel do Estado, atendendo à exigência de se verificar os resultados dos investimentos da administração pública.

Cabe ressaltar que, nos últimos anos, observa-se um movimento global, no âmbito dos poderes legislativos, de discussão em diversos continentes, como Ásia, África e América Latina, acerca da necessidade de se criar políticas nacionais de avaliação no intuito de se analisar a relevância, eficácia, eficiência e efetividade de programas públicos.

No Brasil, esse modelo de gestão por prestação e rendição de contas foi introduzido no início dos anos 1990, justamente quando se instalava no país o regime democrático de administração pública (PINHO e SACRAMENTO, 2009).

O modelo de política de responsabilização implantado na área educacional brasileira é disciplinado por leis que estabelecem padrões curriculares, criação de sistemas de avaliação e descentralização das ações governamentais. Nessa perspectiva, a avaliação educacional em larga escala tornou-se impositiva para levantar informações, monitorar, acompanhar e redirecionar as tomadas de decisões que focalizam a eficiência e a eficácia da educação nacional. Em acordo com o discurso das descentralizações das ações governamentais e do regime de colaboração previstos no Plano Nacional de Educação (decênio 2014-2024), através da Lei $n^{\circ}$ 13.005, de 25 de junho de 2014, em sua submeta 7.36, visa “[...] estabelecer políticas de estímulo às escolas que melhorarem o desempenho no Índice de Desenvolvimento da Educação Brasileira (IDEB), de modo a valorizar o mérito do corpo docente, da direção e da comunidade escolar" (BRASIL, 2014).

Os estados e municípios organizam seus sistemas de avaliação das aprendizagens como mecanismo para subsidiar o processo de formulação e monitoramento das políticas públicas. Exemplo disso é o caso do estado do Ceará, que incorporou, desde o início dos 
anos 1990, a cultura de avaliação e gestão por resultados, com efeitos low-stakes e highstakes.

O fato é que o governo do estado, há mais de uma década, vem apostando na gestão educacional por resultados, fazendo uso da avaliação para emitir rankings, classificações e prêmios, por ter a crença de que tais medidas mobilizam os atores educacionais a desenvolverem um melhor trabalho.

Diante dessa realidade, propõe-se, neste artigo, a discussão sobre a política de responsabilização, reconhecendo e distinguindo suas consequências low-stakes e highstakes no âmbito da gestão pública da educação cearense no decorrer dos últimos 15 anos.

A metodologia utilizada neste escrito é apresentada por meio de estudo descritivo-analítico, desenvolvido através de pesquisa bibliográfica, ou seja, com base em leituras e consultas a livros, artigos científicos, legislações nacionais, dissertações e teses acadêmicas. Trata-se de uma metodologia descritiva, tendo em vista que busca descrever, interpretar, explicar, classificar e atribuir características ao fenômeno analisado; e exploratória, uma vez que intenta identificar e categorizar as experiências do estado do Ceará com políticas de responsabilização com efeitos low-stakes e highstakes.

Vale destacar que este estudo foi extraído da pesquisa de dissertação de mestrado ${ }^{3}$ em Educação Brasileira da primeira autora deste artigo, a qual se apoia nas concepções de pesquisadores renomados, mas avança no sentido de revelar novos achados e experiências, ampliando, assim, o campo de possibilidades de execução e análise da política accountability escolar.

Para um melhor discernimento, o presente artigo encontra-se estruturado em cinco seções. Na primeira parte, veicula-se esta breve introdução. Na segunda, apresentase o panorama da política de responsabilização brasileira. Na terceira parte, evidenciamse as experiências do estado do Ceará com programas de premiação escolar. Na quarta, aborda-se, sucintamente, a repercussão do Prêmio Escola Nota Dez no desempenho

\footnotetext{
3 Esta pesquisa foi desenvolvida entre 2014 e 2015, no mestrado do Programa de Pós-Graduação em Educação Brasileira da Universidade Federal do Ceará (UFC), com o título Os efeitos do Prêmio Escola Nota Dez nos processos pedagógicos das escolas premiadas de Sobral e nas escolas apoiadas de Caucaia no ano de 2019 .
} 
estudantil aferido no teste padronizado do Sistema Permanente de Avaliação da Educação Básica do Ceará (Spaece-Alfa). Na quinta e última parte, expõem-se as considerações finais do estudo.

\section{Panorama da política de responsabilização no Brasil}

A política de responsabilização adotada, comumente, tem como base os resultados da escola, em que o educador é responsabilizado perante as autoridades e o público em geral pela aprendizagem dos alunos e as consequências, reais ou simbólicas, são associadas às medidas usadas para aferir o desempenho dos educandos. Nessa perspectiva, a partir da proficiência alcançada, os gestores públicos estabelecem recompensas ou sanções para os atores educacionais.

As políticas de accountability escolar (de responsabilização) estão implicadas em três componentes articuláveis entre si: a avaliação, a prestação de contas e a responsabilização. Esses componentes possuem forte congruência, constituindo, integradamente, pilares de um processo (AFONSO, 2009a).

A avaliação, parte fundamental desse processo, serve ao propósito de “[...] produzir juízo de valor sobre uma determinada realidade social [...]" (AFONSO, 2010, p. 151), pode ser utilizada antes e/ou depois da fase de responsabilização com o fito de fazer o levantamento, o tratamento e as análises de informações.

O pilar da prestação de contas implica a cobrança por um serviço público de qualidade. As informações geradas, através das avaliações em larga escala, são publicizadas para atestar a eficácia ou o fracasso escolar no sentido de justificar e redirecionar os investimentos públicos, bem como disseminar dados de desempenho escolar com a sociedade, legitimando a aplicabilidade dos recursos públicos oriundos dos impostos pagos pela população.

No tocante à variável da responsabilização, esta atende ao pressuposto da atribuição de responsabilidades dos atos praticados pelos atores educacionais. Numa perspectiva participativa e democrática, a responsabilização implica a capacidade de responder pelas ações empreendidas de modo a obter a assunção autônoma de responsabilidades (AFONSO, 2010). 
Nas duas últimas décadas, assiste-se, nos países capitalistas ocidentais, à disseminação de políticas de accountability, ou seja, de responsabilização, voltadas para o fortalecimento do Estado como mecanismo de controle social e de racionalização dos investimentos públicos.

No campo educacional brasileiro, as pressões circunstanciais dos organismos internacionais de incremento do modelo de accountability têm balizado as atuais políticas adotadas pelo Estado. Dada a valorização das avaliações em larga escala como peça-chave para maior visibilidade e transparência a respeito dos aspectos centrais do processo de aprendizagem, atribuíram ao Estado o papel de avaliador da eficiência e qualidade educacional.

Entretanto, no Brasil, a tendência da política de responsabilização é recente. Até meados da década de 1990, não existiam medidas de avaliação da aprendizagem que produzissem evidências sólidas sobre a qualidade dos sistemas de ensino no país; as políticas educacionais eram formuladas e implementadas sem qualquer avaliação sistemática (CASTRO, 2009). Nesse período, constatou-se a necessidade da criação de estudos que mostrassem, de forma específica, a eficácia ou não do modelo de ensino adotado (currículo) e o desempenho dos alunos (proficiência), estimulando, assim, as primeiras experiências de avaliação educacional (COUTINHO, 2012).

O desenho das políticas de responsabilização iniciou-se com a criação do Sistema de Avaliação da Educação Básica (Saeb), porém ainda de forma muito sutil, haja vista que o seu caráter amostral não permitia seu uso para accountability escolar. "O Saeb, em sua concepção original, seria o melhor exemplo da primeira geração, visto que apresentava caráter diagnóstico e a divulgação dos resultados era restrita, portanto não havia impacto significativo para as escolas" (ARAÚJO, 2016, p. 61).

Com o surgimento da Prova Brasil, avaliação para aferir o desempenho dos alunos de $5^{\circ}$ e $9^{\circ}$ anos do Ensino Fundamental nos componentes de Língua Portuguesa e de Matemática, deu-se início à segunda geração das políticas brasileiras de avaliação, agora não aplicada somente para diagnóstico e planejamento, mas também para monitorar o desempenho individual de todas as escolas públicas de nível fundamental. Essa geração caracterizou-se pela ampla divulgação dos resultados de desempenho escolares, na perspectiva de prestação de contas dos serviços educacionais. 
Com a Prova Brasil e com alguns sistemas estaduais de avaliação, os resultados passaram a ser analisados até o âmbito da escola, permitindo a responsabilização dos gestores e dos professores, causando maior exposição das escolas, mas sem atribuição de recompensas ou sanções. (ARAÚJO, 2016, p. 62)

A política de responsabilização vai alcançar seu ápice a partir do ano de 2005, quando o Ministério da Educação (MEC), através do Instituto Nacional de Estudos e Pesquisas Anísio Teixeira(Inep), implantou o Índice de Desenvolvimento da Educação Básica (Ideb), que se compõe de duas variáveis: o fluxo escolar e as médias de desempenho nas avaliações nacionais.

Como um divisor de águas, o Ideb marcou a forma de fazer política educacional, gerando uma mudança radical nos critérios a serem empregados na avaliação do trabalho escolar e dos responsáveis pelos sistemas de educação. Essas médias referem-se ao desempenho no Saeb para os estados e na Prova Brasil para os municípios. É possível dispor de um valor do indicador para o país como um todo, cada estado, município e escola (FERNANDES, 2007).

A partir do Ideb, inicia-se a terceira geração do sistema de avaliação brasileiro, representada por sistemas estaduais e municipais de avaliação que apresentam políticas de responsabilização de consequências fortes para os atores educacionais, premiando escolas em função de seus resultados. (ARAÚJO, 2016, p. 62)

A sistematização dos processos de avaliação em larga escala influenciou decisivamente na consolidação da política de responsabilização, visto que as estratégias de avaliação padronizadas e seus resultados assumiram o status de tradutores da qualidade, condicionando as escolas a buscarem atingir os índices desejáveis, o que pressupõe a melhoria do desempenho escolar.

A política de responsabilização forte, chamada high-stakes, envolve consequências institucionais cuja operacionalização implica adoção de motivações financeiras, como é o caso dos programas de premiação por mérito, que concebem bonificação para profissionais da educação brasileira de acordo com os resultados obtidos pelos alunos e pelas escolas em testes padronizados. 
A título de experiência, cabe citar o caso do estado do Ceará, uma das entidades federativas do país que vêm consolidando fortemente o viés da avaliação educacional como instrumento de gestão da política de responsabilização low-stakes e high-stakes. Na seção seguinte, destacar-se-á o percurso da política de prestação e rendição de contas no cenário da educação cearense.

\section{A trajetória do estado do Ceará com programas low-stakes e high-stakes}

O estado do Ceará, um dos precursores na implantação de política de responsabilização vem, desde o início dos anos 1990, fortalecendo a cultura de avaliação e gestão por resultados. Essa política, em seus sistemas oficiais, aplica testes ou procedimentos padronizados para avaliar a aprendizagem, emprega critérios que determinam se as escolas apresentam desempenho satisfatório ou insatisfatório, os quais podem gerar consequências fortes ou brandas para os membros da equipe escolar.

Ao longo dos últimos anos, com a implementação das avaliações em larga escala, com a exploração de novas formas de aproveitamento das informações geradas e com a diversificação das práticas de gestão educacional, ocasionou-se uma sofisticação dos sistemas de avaliação no estado do Ceará com o fito de abranger a totalidade de seu alunado e obter maior aproximação da realidade da rede de ensino estadual.

Em 1992, a experiência-piloto de avaliação anual do desempenho dos alunos de $5^{\circ}$ e $9^{\circ}$ anos envolveu uma amostra de 156 escolas da rede estadual e 14.600 estudantes de $5^{\circ}$ e $9^{\circ}$ anos do Ensino Fundamental da cidade de Fortaleza. Até 1996, a avaliação via Sistema Permanente de Avaliação da Educação Básica do Ceará (Spaece), em Português e Matemática, foi feita de maneira tradicional (VIEIRA, 2007).

Em 2001, a metodologia da prova foi radicalmente alterada para se tornar um Computer Assisted Testing (CAT), sendo o programa renomeado para Spaece-Rede. O Spaece passou a aplicar os testes pela internet. Os discentes incluídos nas amostras por série respondiam aos testes em telessalas equipadas com computadores.

Pelo novo sistema, a média do desempenho nos $5^{\circ}$ e $9^{\circ}$ anos passou a ser considerada como o indicador da qualidade da escola. Com efeito, elaborou-se o Prêmio Educacional Escola do Novo Milênio (PEENM) - Educação Básica de Qualidade no Ceará, 
que estabelecia a conexão entre os resultados da avaliação do Spaece-Rede e o Projeto de Melhoria da Escola. "O pressuposto do programa é que os profissionais da educação se mostram mais dispostos a cooperar para obter resultados coletivos quando está em jogo um incentivo financeiro baseado nesse desempenho" (BROOKE, 2006, p. 387).

A Lei $n^{\circ}$ 13.203, de 21 de fevereiro de 2002 (CEARÁ, 2002), designava que o PEENM - Educação Básica de Qualidade no Ceará deveria ser outorgado aos membros das equipes das 100 melhores escolas, sendo que, para as 50 melhores escolas, o prêmio seria de $100 \%$ do valor especificado; para as demais, seria de 50\%. Para concorrer ao referido prêmio, as escolas precisavam aderir ao Projeto de Melhoria da Escola e definir metas voltadas à melhoria do ambiente físico, redução das taxas de evasão e aumento dos índices de aprovação escolar. O prêmio era uma recompensa em dinheiro concedida quando as médias das escolas alcançavam a nota cinco ou mais (até dez), e correspondia a $\mathrm{R} \$ 800,00$ para os docentes temporários e permanentes em tempo integral e $\mathrm{R} \$ 300,00$ para o pessoal administrativo. Também havia premiação destinada aos melhores educandos.

Nesse caso, conforme Araújo (2016), o PEENM - Educação Básica de Qualidade no Ceará foi a primeira experiência com a política de responsabilização. Em parte, verificamse consequências low-stakes (de baixo valor) pelo uso dos resultados da avaliação para promover o reconhecimento público das escolas, ou seja, da publicização das proficiências escolares dos participantes do programa. Entretanto, também há sinais de efeitos high-stakes (de alto valor), ao conceder incentivos monetários aos profissionais de educação e premiações aos discentes. Contudo, ressalta Araújo que:

[...] em decorrência de a participação ser por adesão ao Projeto de Melhoria da Escola, nem todas as unidades escolares municipais e estaduais participavam da premiação. As consequências dos resultados de aprendizagens insuficientes ainda não eram significativas e de alto impacto, o prêmio tinha pouca repercussão social e moderada competitividade entre as escolas. (ARAÚJO, 2016, p. 65)

Em 2004, o Spaece passou a ser incorporado à rede estadual e municipal de ensino, avaliando o maior contingente de escolas desde sua criação. A partir dessa significativa mudança, a Lei nº 13.203/2002 (CEARÁ, 2002) foi revogada pela Lei nº 13.541, 
de 22 de novembro de 2004 (CEARÁ, 2004), instituindo-se o Programa de Modernização e Melhoria da Educação Básica (PMMEB). Esse programa concedia o Selo de Qualidade da Educação Básica do estado do Ceará em dois níveis - Selo Certificação e Selo Escola Destaque do Ano - para as unidades escolares participantes do programa que apresentavam melhorias relativas nos indicadores de rendimento - taxa de aprovação e taxa de abandono - e nos resultados alcançados no desempenho dos estudantes medido por meio do Spaece (VIEIRA, 2007).

Ante o modelo do PMMEB, que continuou ininterruptamente até 2007, percebe-se que essa versão se enquadra como instrumento de gestão por responsabilização com efeitos low-stakes, visto que sua consequência limitava-se ao caráter simbólico mediante a aquisição da certificação e do selo das escolas destaque. Contudo, Araújo (2016) acrescenta que nesse evento, embora a gestão pública não associasse as melhorias dos indicadores de rendimentos às premiações em forma de incentivos financeiros aos profissionais de educação, a tendência da política de responsabilização estava presente no cenário da educação cearense. Desse modo, o PMMED era:

[...] uma maneira de prestar contas à sociedade sobre os serviços educacionais prestados e, de certa forma, conferir quais as escolas que não estavam cumprindo as metas. As instituições escolares que não recebiam a certificação e/ou o selo eram estigmatizadas pela opinião popular como escolas de má qualidade. (ARAÚJO, 2016, p. 66)

A partir de 2007, a abrangência do Spaece incorporou a avaliação da alfabetização e expandiu a avaliação para as três séries do Ensino Médio de forma censitária. Dessa maneira, o Spaece passa a ter três focos: Avaliação da Alfabetização - Spaece-Alfa ( $2^{\circ}$ ano), Avaliação do Ensino Fundamental ( $5^{\circ}$ e $9^{\circ}$ anos) e Avaliação do Ensino Médio $\left(1^{\mathrm{a}}, 2^{\mathrm{a}}\right.$ e $3^{\mathrm{a}}$ séries).

A idealização do Spaece-Alfa surge em decorrência da prioridade do governo na alfabetização das crianças logo nos primeiros anos de escolaridade, expressa através do Programa Alfabetização na Idade Certa (Paic) ${ }^{4}$. O Spaece-Alfa consiste numa avaliação

\footnotetext{
${ }^{4}$ O Programa de Alfabetização na Idade Certa (Paic) foi lançado oficialmente em 2007 com o objetivo de garantir o direito da criança de aprender na idade certa. É constituído de cinco eixos: eixo de alfabetização, eixo de gestão municipal, eixo de educação infantil, eixo de literatura infantil e formação de leitor e eixo de avaliação externa (CEARÁ. Secretaria da Educação do Governo Do Ceará, 2015).
} 
anual, externa e censitária para identificar e analisar o nível de proficiência em leitura dos alunos do $2^{\circ}$ ano do Ensino Fundamental das escolas da rede pública (estaduais e municipais), possibilitando construir um indicador de qualidade sobre a habilidade em leitura de cada educando, o que permite estabelecer comparações com os resultados das avaliações realizadas pelos municípios e pelo Governo Federal (Provinha Brasil).

Em 2007, em nome de uma gestão pública por resultados, foi criada a Lei nº 14.023 (CEARÁ, 2007), do Ceará, que designou a distribuição da cota estadual do Imposto sobre Circulação de Mercadorias e Prestação de Serviços (ICMS) para os municípios, de acordo com os resultados do Spaece. Estabeleceu-se que:

[...] 18\% dos $25 \%$ da arrecadação do ICMS serão distribuídos 'em função do Índice Municipal de Qualidade Educacional de cada município, formado pela taxa de aprovação dos alunos do $1^{\circ}$ ao $5^{\circ}$ ano do Ensino Fundamental e pela média obtida pelos alunos de $2^{\circ}$ e $5^{\circ}$ ano da rede municipal em avaliações de aprendizagem' (Art. $1^{\circ}$, Parágrafo Único, II). (BROOKE e CUNHA, 2011, p. 43)

Pelo componente de responsabilização inerente à distribuição de recursos com base no desempenho, as consequências dessa legislação têm sido a mobilização dos prefeitos e uma concorrência para melhorar os resultados nos municípios.

Em 2009, o estado do Ceará concebeu leis que disciplinam programas focados nos resultados escolares, vinculados ao repasse de recursos atrelados ao desempenho dos alunos, premiação por mérito e bonificação como reconhecimento ao cumprimento de metas e melhoria no aprendizado dos discentes, como referido no excerto a seguir.

O Prêmio Escola Nota 10, o Plano de Desenvolvimento da Educação - PDE e o Prêmio Aprender pra Valer são marcados por uma tendência atual da política de responsabilização e bonificação dos atores educacionais pelos resultados das avaliações. (SPAECE/IDE-Alfa, SPAECE/IDE-5 e SPAECE/Ensino Médio) (BROOKE e CUNHA, 2011, p. 26)

Destaca-se como uma das ações de incentivos com consequências high-stakes (de alto valor) para as escolas e para seus atores, o Prêmio Escola Nota Dez. Atualmente, esse prêmio é disciplinado pela Lei Estadual n 15.923/15 (CEARÁ, 2015a), regulamentada pelo Decreto $n^{\circ} 32.079 / 16$ e funciona como: 
Política indutora para as escolas melhorarem seus resultados; Como política apoiadora às escolas com menores resultados; Está subsidiado em um modelo de aprendizagem institucional focado na disseminação de boas práticas de gestão e pedagógica; Fortalecer a melhoria da qualidade na aprendizagem dos alunos de $2^{\circ}$ e $5^{\circ}$ anos do ensino fundamental da rede pública. (CEARÁ. Secretaria da Educação do Governo do Ceará, 2013, p. 1)

Faz-se mister considerar que o Prêmio Escola Nota Dez tem grande repercussão em todo o estado do Ceará, por abranger a rede pública, com mais de 4.500 escolas envolvidas, e também por incidir sobre o processo de alfabetização no $2^{\circ}$ ano, etapa condicionante para continuidade da escolarização.

Esse evento acontece anualmente, do qual todos os 184 municípios do estado do Ceará participam mediante os resultados do Spaece-Alfa, Spaece $5^{\circ}$ e Spaece $9^{\circ}$. Com efeito, o Prêmio Escola Nota Dez faz uso dos resultados dessa avaliação em larga escala para verificar a eficiência da aprendizagem dos alunos, comparar, classificar e premiar.

Concede-se premiação para as 150 escolas com os melhores resultados, que obtenham Índice de Desempenho Escolar (IDE-Alfa) entre 8.5 e 10.0 e Índice de Desempenho Escolar (IDE-5) entre 7.5 e 10.0. O prêmio também oferece aporte financeiro às 150 escolas com os mais baixos desempenhos. Como condicionantes, a escola, para ser agraciada com o prêmio, tem que ter no mínimo 20 estudantes matriculados na série em questão, bem como ter pelo menos 90\% desses avaliados. Há ainda a exigência de que a instituição, para receber o prêmio, precisa, no município onde se localiza, que pelo menos $70 \%$ dos alunos do $2^{\circ}$ ou $5^{\circ}$ ano alcancem o nível “desejável” na escala Spaece.

A premiação para as 150 melhores escolas é de $\mathrm{R} \$ 2.000,00$ por aluno e a contribuição de auxílio financeiro para as 150 escolas de baixo desempenho é de $\mathrm{R} \$ 1.000,00$ por discente. Especialmente para as escolas premiadas, do total dos recursos recebidos, $20 \%$ são atribuídos para a bonificação dos profissionais de educação que colaboraram diretamente para o cumprimento das metas; 70\% devem ser aplicados em obras, pequenas reformas, material didático, ou seja, empregados em recursos físicos e estruturais permanentes; os $10 \%$ restantes destinam-se às visitas técnicas às escolas apoiadas. 
Diante desse modelo de premiação, destaca Araújo (2016) que essa política de alocação de recursos, com base em resultados das avaliações do Spaece, apresenta impacto de consequências ou responsabilização high-stakes (de alto valor), visto que:

A distribuição de recursos condicionada ao melhor desempenho escolar provoca: a competição entre as escolas, a reorientação das práticas pedagógicas, que se voltam para os testes padronizados, e a preleção de conteúdos curriculares de acordo com as matrizes das avaliações externas. Essas reações das escolas em busca de atingirem o status de Escolas Nota Dez são fundadas nos princípios da meritocracia, do tecnicismo e da produtividade. Estimulam a aprendizagem memorística e reprodutivista dos conteúdos com vistas a conquistar metas e alcançar resultados. (ARAÚJO, 2016, p. 69)

As escolas premiadas são aquinhoadas com recursos até vultosos, viram destaque nos noticiários locais e recebem o reconhecimento público da sua qualidade. Por outro lado, as não premiadas sofrem prejuízos pela privação de melhores condições de trabalho, perda de incentivos de bonificação e ainda passam por situações de constrangimento simbólico com a publicidade do insucesso escolar (MIZALA e ROMAGUERA, 2003).

Em face dessa trajetória da política de responsabilização escolar, percebe-se que ocorreu um incremento no uso dos resultados do sistema de avaliação educacional do Ceará a fim de regular as práticas pedagógicas e de gestão que, com efeito, vêm gerando melhorias no desempenho estudantil. Esse indicativo de ascensão da proficiência escolar das crianças do Ensino Fundamental, séries iniciais, especificamente no processo de alfabetização escolar, será assunto tratado na próxima seção.

\section{Marcas e ruídos do Prêmio Escola Nota Dez no índice de alfabetização escolar do estado do Ceará}

Com o propósito de mudar a realidade educacional do estado, priorizando a alfabetização, o governo do Ceará criou ações estruturantes (Paic, Spaece-Alfa, distribuição da cota estadual ICMS e o Prêmio Escola Nota Dez) para reverter os baixos índices de alfabetização escolar. Esse conjunto de ações foi inaugurado no ano de 2007 
com a instauração do Programa Alfabetização na Idade Certa (Paic), uma política pública de cooperação entre Governo do Estado e municípios cearenses com a finalidade de apoiar os municípios para alfabetizar todos os alunos da rede pública de ensino até os sete anos, especificamente até o final do $2^{\circ}$ ano do Ensino Fundamental.

Em decorrência da estruturação do Paic, foi incorporado ao eixo de avaliação externa o Spaece-Alfa, introduzindo assim a avaliação de leitura dos alunos do $2^{\circ}$ ano do Ensino Fundamental das escolas da rede pública (estaduais e municipais).

Outra ação estruturante para melhorar os indicadores de alfabetização escolar foi a criação, em 2007, da Lei $n^{\circ}$ 14.023/07, (CEARÁ, 2007) do Ceará, que distribui a cota estadual do Imposto sobre Circulação de Mercadorias e Prestação de Serviços (ICMS) para os municípios, de acordo com os resultados do Spaece. A distribuição de recursos com base no desempenho discente é um componente de responsabilização que tem mobilizado os prefeitos a buscarem melhorar os indicadores educacionais de seus municípios, visto que o repasse do ICMS está condicionado aos resultados dos alunos nas proficiências em Português e Matemática dos $2^{\circ}$ e $5^{\circ}$ anos do Ensino Fundamental.

Segundo Burgos, Santos e Ferreira (2012), tais ações foram implementadas em decorrência dos resultados de uma pesquisa amostral com 48 municípios, realizada em 2004, pelo Comitê Cearense para Eliminação do Analfabetismo Escolar (CCEAE), da Assembleia Legislativa do Estado do Ceará. Seus resultados foram publicados no Relatório final do Comitê Cearense para a eliminação do analfabetismo escolar: educação de qualidade começando pelo começo. De modo geral, ficou evidenciado que: "[...] 39\% das crianças do $3^{\circ}$ ano não leram o texto, $42 \%$ leram sem fluência, reproduzindo letras ou soletrando sílabas, e apenas 20\% leram com fluência, de forma artificial (11\%) ou adequada (9\%)" (AGUIAR, GOMES e CAMPOS, 2006, p. 37).

O comitê tocou fundo no problema central da educação pública cearense, denunciando o analfabetismo em idade escolar e, acima de tudo, indicando para as instâncias estadual e municipal a importância da tomada de posição e incorporação em suas agendas da construção de uma política de alfabetização para o Ceará.

No estado do Ceará, em 2007, período em que o Paic entrou em definitivo na agenda do governo, "[...] cerca de $33 \%$ das crianças de 7 anos não estavam alfabetizadas e 
14,7\% estavam com Alfabetização Incompleta. Apenas 9,9\% tinham nível Suficiente e 29,9\% Desejável. Ou seja, quase metade das crianças estavam com níveis baixos de alfabetização" (CEARÁ. Secretaria da Educação do Governo do Ceará, 2015, p. 4).

Como resultante dessa conjuntura, ao longo dos últimos dez anos, verificou-se que a participação e a proficiência das competências de alfabetização evoluíram. Segundo a Seduc/CE, em 2007, o percentual de alunos alfabetizados era de 30\%; em 2010, ascendeu para 54,9\%; e, em 2016, permaneceu evoluindo, atingindo 73,9\% de crianças com nível “desejável” (CEARÁ, 2015b).

Percebe-se que é expressivo o movimento ascendente das médias de proficiências em nível “desejável”. Conforme nos mostra o gráfico da imagem adiante, no período de 2007 a 2016, a concentração maior passou para o intervalo “desejável”.

Gráfico 1 - Histórico do percentual de alunos por padrão de desempenho no Spaece-Alfa (2007 a 2016)

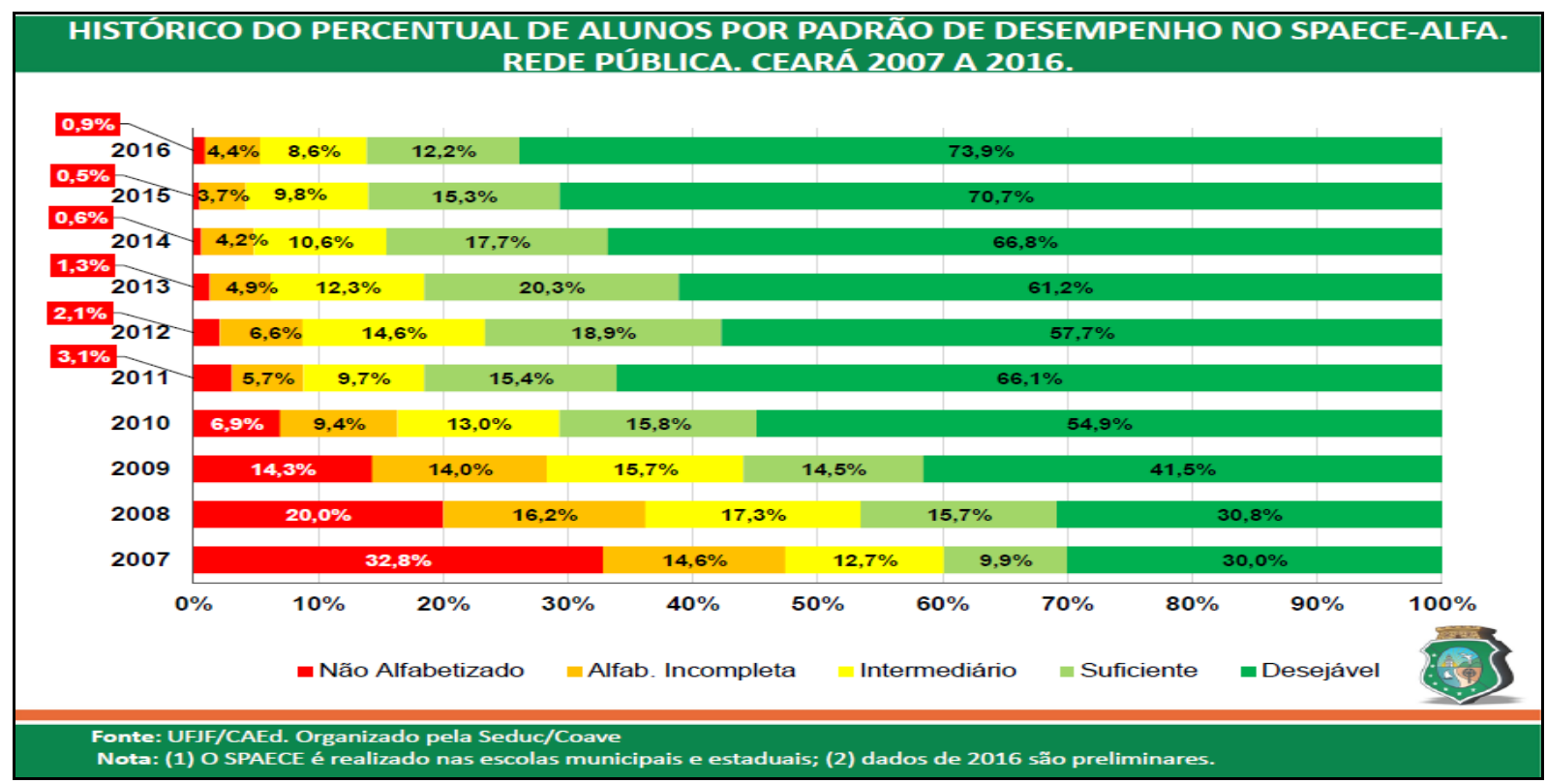

Fonte: UFJF/ Caed. Organizado pela Seduc/Coave (2016).

Atesta-se que o percentual de alunos com proficiência de desempenho “desejável” obteve um aumento significativo, passando de 41,5\% em 2009 para 54,9\% em 2010, representando 13,4\% de aumento, logo após a implantação do Prêmio Escola Nota Dez. Por outro lado, percebemos um decréscimo de alunos do $2^{\circ}$ ano não alfabetizados 
de $32,8 \%$ em 2007 , caindo para $0,9 \%$ em 2016 , reduzindo em $31,9 \%$, sinalizando um movimento de redução das taxas de analfabetismo escolar alavancado pelo Paic.

Em que pese aos diversos programas de responsabilização desenvolvidos pela Secretaria da Educação do Ceará (Seduc), através do Spaece, neste tópico do artigo circunscreve-se especificamente o Prêmio Escola Nota Dez, visto que tem sido objeto de especial atenção devido à sua repercussão no crescimento do percentual de alunos alfabetizados ao final do $2^{\circ}$ ano, como demonstra a figura a seguir:

Figura 1. Resultado dos estudantes do $2^{\circ}$ ano por padrão de desempenho no Spaece-Alfa Ceará (2007-2013)

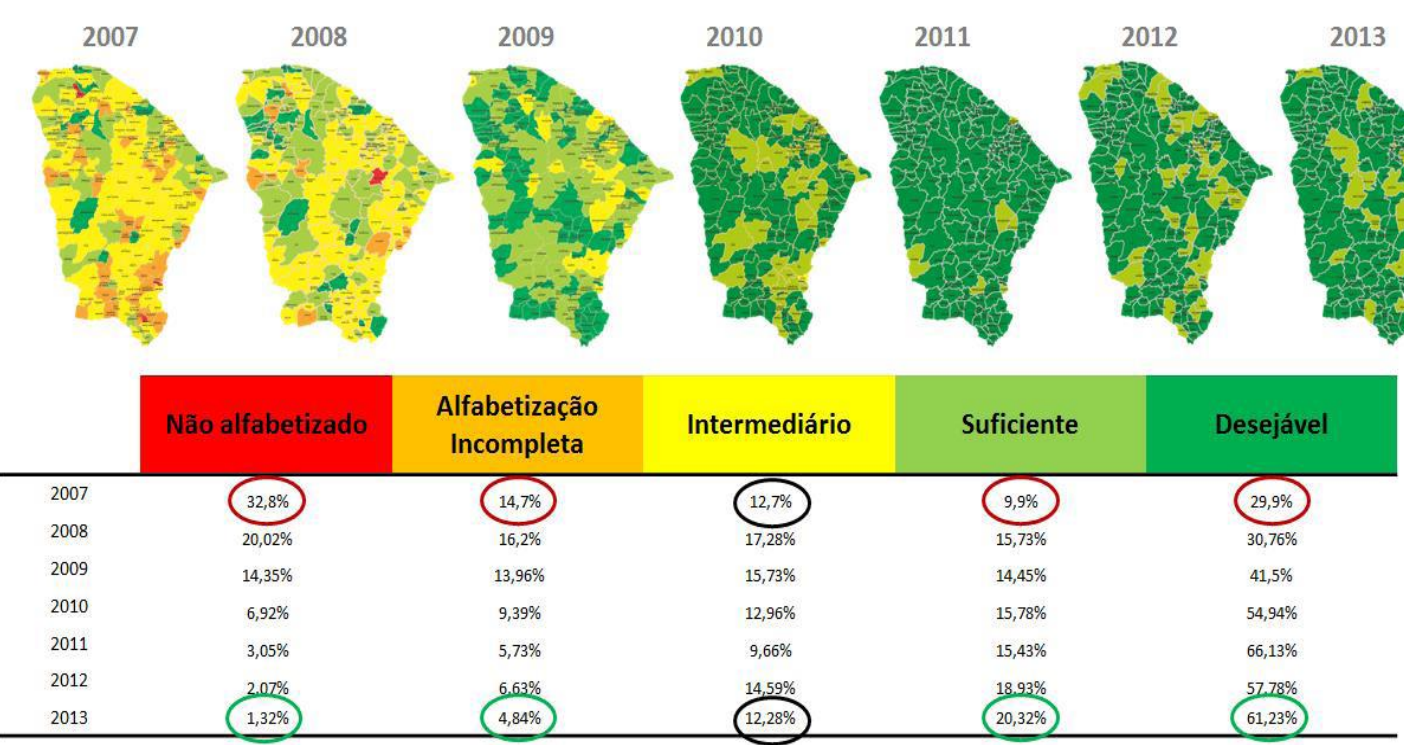

Fonte: Coave/Seduc-CE/Spaece-Alfa (2014).

Conforme a figura 1, no ano de 2007, a concentração maior dos estudantes por desempenho era no intervalo da proficiência "não alfabetizado"; em 2008 e 2009, passou para o "desejável”, porém com quantitativo significativo de educandos ainda "não alfabetizados". Nos anos posteriores, 2010 a 2013, houve uma retração de alunos "não alfabetizados" e de "alfabetização incompleta", com elevação significativa dos discentes com proficiência "suficiente" e "desejável”.

Observa-se que, no período de 2009 a 2013, houve expressivo movimento ascendente das médias de proficiências em nível “desejável” nos municípios cearenses, que corresponde ao percurso de implementação/execução da política de responsabilização estadual. Os dados estatísticos dos índices de alfabetização são 
algumas das marcas que têm revelado o efeito da política indutora empreendida pelo Prêmio Escola Nota Dez para que as escolas melhorassem seus resultados no IDE-Alfa.

Esses dados, também descritos no estudo de mestrado da primeira autora deste artigo, revelam um avanço a favor do padrão de qualidade estabelecido pelas políticas educacionais, o qual é nomeado na referida dissertação de avanço “verde", devido à cor que representa quando o aprendiz desenvolve habilidades "desejáveis" próprias de um leitor, e "aligeirado", porque se realizou em curto espaço de tempo, maximizando o desempenho cognitivo, em detrimento do curso de desenvolvimento integral da criança.

No mapa da alfabetização das crianças cearenses, o avanço "verde" não está associado estritamente à cultura de avaliação que foi empreendida pelo Paic, mas, sobretudo, ao modelo de gestão por resultados do Prêmio Escola Nota Dez, de responsabilização high-stakes, que faz frente para impulsionar e alavancar as melhorias no padrão de desempenho da alfabetização na idade certa.

Sob a lógica meritocrática, a referida premiação associa qualidade educacional, estritamente, ao desempenho escolar e induz as escolas a buscarem os melhores resultados, a qualquer custo, a fim de que possam ser agraciadas com incentivos financeiros e bonificação, reproduzindo o ideário de educação como mercado e o ensino como mercadoria.

Em face disso, devem-se considerar também os propensos ruídos desse modelo de responsabilização de consequências fortes no processo de aprendizagem. Nessa direção, Araújo (2016) adverte que o uso dos high-stakes tests, com foco na predição dos objetivos e na validação curricular, tende a comprimir o currículo escolar e a substituir os esforços de ensino pela mera modelagem dos alunos para os testes de proficiência, o que, consequentemente, proporcionaria uma melhoria nos dados do Spaece.

Outro ruído suscetível está associado ao efeito psicológico da premiação que essa política de publicização e estandardização dos resultados do Spaece tende a causar nas escolas. A tendência é a de que gestores e professores escolares, preocupados com a repercussão da divulgação dos rankings e com a emissão de valor da opinião pública, sintam-se pressionados a empreenderem mais energia, força e trabalho para atingir o 
padrão estipulado de eficácia e eficiência escolar, gerando tensões e conflitos interpessoais.

Por fim, o Prêmio Escola Nota Dez, como política de responsabilização de consequências high-stakes, ora deixa marcas propositivas no mapa da alfabetização no estado do Ceará, ora induz a ruídos prejudiciais aos processos pedagógicos escolares. Sendo necessários novos estudos que possam dar conta de investigar o impacto desse desenho de política, tanto no desempenho quanto nas práticas de gestão escolar e de docência.

\section{Considerações finais}

O estado do Ceará, ao definir como eixo o pacto pela alfabetização escolar, introduziu a política de responsabilização de consequências simbólicas e factuais para os atores educacionais, por meio da: pactuação de metas de alfabetização por município; instituição da avaliação da alfabetização: Spaece-Alfa; definição de um indicador de proficiência dos alunos do $2^{\circ}$ ano, medido através de uma avaliação externa anual; vinculação da distribuiç̧ão do Imposto sobre Circulação de Mercadorias e Serviços (ICMS) a indicadores municipais; e implantação de políticas de incentivo, como o Prêmio Escola Nota Dez.

A experiência do Ceará com as políticas de responsabilização de efeitos low-stakes e high-stakes vem servindo à necessidade do estado de controlar a qualidade da educação e de prestar contas sobre os financiamentos das políticas educacionais, mas também se compreende que essas avaliações externas e os mecanismos de responsabilização incidiram na elevação do percentual de alunos do $2^{\circ}$ ano com proficiência "desejável”, logo na superação dos níveis de analfabetismo no estado.

A conclusão a que se chega é a de que o estado do Ceará legitima os componentes da política de responsabilização, especialmente no Prêmio Escola Nota Dez, pois faz uso dos resultados do Spaece para publicização dos rankings escolares, atribuição de mérito e demérito das escolas, premiação institucional, bonificação docente e também como medidas administrativas para ajudar e/ou fechar escolas com níveis de desempenho considerados insuficientes. 
Essa maneira de conduzir a educação aumenta a relevância dos resultados das avaliações e, por conseguinte, tende a reorientar o trabalho pedagógico, interferindo no currículo, na forma de ensinar e de avaliar, bem como na finalidade da escolarização. Repercussões que estão subjacentes aos dados do Spaece e merecem ser levadas a cabo em futuras investigações, como por exemplo, os dispositivos pedagógicos às avessas (promessas de recebimento de prêmios, medalhas e honras ao mérito) que a equipe escolar empreende durante todo o ano letivo para alcançar a performance de excelência explicitada nos testes padronizados, condicionando as crianças a agirem a partir de princípios e práticas da racionalidade mercantil e produtivista.

\section{Referências}

AFONSO, Almerindo Janela. Nem tudo o que conta em educação é mensurável ou comparável. Crítica à accountability baseada em testes estandardizados e rankings escolares. Revista Lusófona de Educação, v. 13, n. 1, p. 13-29, 2009 a.

AFONSO, Almerindo Janela. Políticas avaliativas e accountability em educação. Subsídios para um debate ibero-americano. Sísifo: Revista de Ciências de Educação, v. 9, p. 57-70, 2009b.

AFONSO, Almerindo Janela. Um olhar sociológico em torno da accountability em educação. In: M. T. Esteban e A. J. Afonso (Orgs.). Olhares e interfaces: reflexões críticas sobre a avaliação. São Paulo: Cortez. p. 147-170, 2010. 
AGUIAR, Rui Rodrigues, Gomes, Ivo Ferreira; CAMPOS, Márcia Oliveira Cavalcante. (Orgs.). Relatório final do Comitê Cearense para a Eliminação do Analfabetismo Escolar: educação de qualidade começando pelo começo. Fortaleza: Assembleia Legislativa do Ceará, 2006.

ANDRIOLA, Wagner Bandeira. Apresentação de um modelo teórico destinado à avaliação dos Programas Estaduais de Qualificação Profissional. Ensaio: Avaliação de Políticas Públicas em Educação, v. 6, n. 19, p. 259-266, 1998.

ANDRIOLA, Wagner Bandeira. Evaluación: la vía para la calidad educativa. Ensaio: Avaliação de Políticas Públicas em Educação, v. 7, n. 25, p. 355-368, 1999.

ARAÚJO, Karlane Holanda. Os efeitos do Prêmio Escola Nota Dez nos processos pedagógicos das escolas premiadas de Sobral e das apoiadas de Caucaia no ano de 2009. 2016. (Dissertação de Mestrado em Educação) - Universidade Federal do Ceará, Programa de Pós-Graduação em Educação Brasileira, Fortaleza, 2016.

BRASIL. Lei n 13.005, de 25 junho de 2014.). Aprova o Plano Nacional de Educação PNE e dá outras providências. Diário Oficial da União, Brasília, 26 junho de 2014.

BROOKE, Nigel. O futuro das políticas de responsabilização educacional no Brasil. Cadernos de Pesquisa, v. 36, n. 128, p. 377-401, 2006.

BROOKE, Nigel; CUNHA, Maria Amália. A avaliação externa como instrumento da gestão educacional nos estados. Estudos e Pesquisas Educacionais, v. 2, p. 17-79, 2011.

BURGOS, Marcelo Baumann; SANTOS, Maéve Melo dos; FERREIRA, Patrícia Valesca Gomes. Avaliação, alfabetização e responsabilização: os casos de Minas Gerais e Ceará. Pesquisa e Debate em Educação, v. 2, n. 2, p. 24-44, 2012.

CASTRO, Maria Helena Guimarães de. Sistemas de avaliação da educação no Brasil: avanços e novos desafios. Perspectiva, São Paulo v. 23, n. 1, p. 5-18, 2009.

CEARÁ. Lei n 13.203, de 21 de fevereiro de 2002. Institui o prêmio educacional "Escola do Novo Milênio - Educação Básica de Qualidade no Ceará”, relativo ao ano de 2001, e dá outras providências. Diário Oficial do Estado, Fortaleza, 25 fevereiro de 2002.

CEARÁ. Lei n 13.541, de 22 de novembro de 2004. Institui o Programa de Modernização e Melhoria da Educação Básica - PMMEB, nos estabelecimentos de ensino da Rede Pública do Estado do Ceará. Diário Oficial do Estado, Fortaleza, 24 novembro de 2004.

CEARÁ. Lei $n^{\circ}$ 14.023, de 17 de dezembro de 2007. Modifica dispositivos da Lei $n^{\circ} 12.612$, de 7 de agosto de 1996, que define critérios para distribuição da parcela de receita do produto e arrecadação do Imposto Sobre Operações Relativas à Circulação de Mercadorias e sobre Prestações de Serviços de Transporte Interestadual e Intermunicipal e de Comunicação - ICMS, pertencente aos municípios, e dá outras providências. Diário Oficial do Estado, Fortaleza. 17 dezembro de 2007. 
CEARÁ. Lei nº 15.052, de 6 de dezembro de 2011. Institui o Prêmio Escola Nota Dez, destinado a premiar as escolas públicas com melhores resultados de aprendizagem no segundo e quinto anos de ensino fundamental, e dá outras providências. Diário Oficial do Estado, Fortaleza, 12 dezembro de 2011.

CEARÁ. Secretaria da Educação do Governo do Ceará. . Prêmio Escola Nota 10. Fortaleza: Seduc, 2013. Recuperado de: http://www.paic.seduc.ce.gov.br/index.php/o-paic/premioescola-nota-10. Acesso em: 05 de maio de 2016.

CEARÁ. Lei $n^{\circ} 15.923$, de 15 de dezembro de 2015, regulamentada pelo Decreto $n^{\circ} 32.079$, de 9 de novembro de 2016. Modifica a Lei Estadual $n^{\circ}$ 15.052, de 6 de dezembro de 2011, que define premiação para as escolas públicas de $2^{\circ}, 5^{\circ}$ e $9^{\circ}$ anos do Ensino Fundamental com os melhores resultados na avaliação do Spaece, bem como apoio financeiro às escolas de $5^{\circ} \mathrm{e}$ $9^{\circ}$ ano com os menores resultados nesta avaliação. Diário Oficial do Estado do Ceará, Fortaleza, 16 dez. 2015 a.

CEARÁ. Resultados de desempenho e participação no Spaece-Alfa 2014 em Língua Portuguesa para o Ceará, Credes, Municípios, Regionais e Distritos de Fortaleza e Escolas. Fortaleza: Seduc, 2015b.

CEARÁ. Secretaria da Educação do Governo do Ceará. . Resultados de desempenho e participação no SPAECE-Alfa 2014 em língua portuguesa para o Ceará, Credes, Municípios, Regionais e Distritos de Fortaleza e Escolas. Fortaleza: Seduc, 2015. Recuperado de: http://www.seduc.ce.gov.br/images/spaece/13julho2015/planilhao_ide_spaece_2014_Ip_2ef_alf a_150608_v2.xls. Acesso em: 20 de maio de 2016.

CEARÁ. Secretaria da Educação do Governo do Ceará. Prêmio Escola Nota Dez. Fortaleza: Seduc, [200-]. Recuperado de: http://www.paic.seduc.ce.gov.br/index.php/o-paic/premioescola-nota-10. Acesso em: 22 de maio de 2016.

COUTINHO, Magno Sales. Avaliação externa e currículo: possíveis impactos e implicações no processo de ensino-aprendizagem. In: ENCONTRO NACIONAL DE DIDÁTICA E PRÁTICAS DE ENSINO, 16, Campinas. Anais [...]. Campinas: Unicamp, 2012. p. 2902-2912.

FERNANDES, Reynaldo. Índice de Desenvolvimento da Educação (Ideb). Brasília: MEC, 2007.

GARDNER, David Pierpont. et al. A nation at risk: the iperative for educational reform. An open letter to the American people. A report to the nation and the secretary of education. Washington: National Commission on Excellence in Education, 1983.

GIANNETTI, Eduardo Fonseca. Auto-Engano. 1997.

MIZALA, Alejandra; ROMAGUERA, Pilar. Rendimiento escolar y premios por desempeño: la experiencia latino americana. Santiago: Universidad de Chile, 2003. 
PINHO, José Antonio Gomes de e SACRAMENTO, Ana Rita Silva. Accountability: já podemos traduzi-la para o português? Revista de Administração Pública, v. 43, n. 6, p. 1343-1368, 2009.

SEDUC. Coordenadoria de Avaliação e Acompanhamento da Educação (COAVE). Resultado Spaece 2016: apresentação do powerpoint. Recuperado de: http://aprece.org.br/wp-content/uploads/2017/02/aprece-associacao-dos-municipios-doestado-do ceara_spaece_2007_a_2016_preliminar_spaece_2ef_5ef_gef_vfinal_sem_participacaopdf.pdf. Acesso em: 08 de junho de 2016.

SEDUC. MAIS PAIC. Mapas dos Resultados do Spaece. Recuperado de: http://www.paic.seduc.ce.gov.br/index.php/resultados/mapas-dos-resultados Acesso em: 10 de junho de 2016.

TREVISAN, Andrei Pittol; BELLEN, Hans Michael van. . Avaliação de políticas públicas: uma revisão teórica de um campo em construção. Revista de Administração Pública, v. 42, n. 3, p. 529-550, 2008.

VIEIRA, Sofia Lerche. Gestão, avaliação e sucesso escolar: recortes da trajetória cearense. Estudos Avançados, v. 21, n. 60, p. 45-60, 2007.

Recebido em: 20/11/2016 Revisões requeridas em: 19/12/2017 Aprovado em: 06/02/2018

Universidade do Estado de Santa Catarina - UDESC Programa de Pós-Graduação em Educação - PPGE Revista Linhas Volume 20 - Número 42 - Ano 2019 revistalinhas@gmail.com 